Pacific Journal of Mathematic 


\title{
MAPPING SOLENOIDS ONTO STRONGLY SELF-ENTWINED, CIRCLE-LIKE CONTINUA
}

\author{
J. T. Rogers, Jr.
}

\begin{abstract}
A circle-like continuum $C$ is self-entwined if there exists a sequence $\left\{C_{i}\right\}$ of circular chains which define $C$, a point $p$ in $C$, and a sequence $\left\{D_{i}\right\}$ such that, for each $i,(1)$ either $D_{i}$ is a subchain of $C_{i}$, or $D_{i}=C_{i}$, (2) $D_{i+1}$ circles at least twice in $C_{i}$, (3) $C_{i+1}$ circles at least once in $C_{i}$, and (4) the point $p$ is in the first link of $D_{i}$. If, in addition, each $D_{i+1}$ circles more times in $C_{i}$ than $C_{i+1}$ circles in $C_{i}$, then $C$ is said to be strongly self-entwined.

The purpose of this paper is to prove the following.

Theorem 1. No solenoid can be mapped onto a strongly self-entwined, circle-like continuum.
\end{abstract}

We show that each self-entwined, circle-like, plane continuum is strongly self-entwined; hence Theorem 1 implies that no solenoid can be mapped onto a self-entwined, circle-like, plane continuum.

Theorem 1 has another interesting corollary. Let $n$ be a natural number greater than one. Let $V_{n}$ denote the circle-like plane continuum which is the common part of a descending sequence $\left\{C_{i}\right\}$ of circular chains such that $C_{i+1}$ circles $n$ times in $C_{i}$ in the positive direction and then $n-1$ times in the negative direction (see [1] for the definition of circling) and such that the first link of $C_{i}$ contains the closure of the first link of $C_{i+1}$. The continuum $V_{n}$ is obviously selfentwined, so no solenoid can be mapped onto $V_{n}$. This contrasts with a result [6] of J. W. Rogers, Jr., who has shown that each member of an analogous class of arc-like continua is a continuous image of each solenoid.

We assume the terminology and definitions of [3]. We use the equivalent definition of self-entwined, circle-like continuum given in [3]. We assume that each factor space of an inverse sequence is a triangulation of the unit circle $C$ and that each bonding map is a surjective, piecewise-linear map of nonnegative degree. We also assume that, under these maps, the image of each vertex is either a vertex or a midpoint of a one-simplex, and that adjacent vertices are mapped into a simplex. Such inverse sequences are called barycentric inverse sequences. Each circle-like continuum has such an inverse limit representation [4, Lemma 8].

We redefine strongly self-entwined, circle-like continua in the terminology of [3]. If $X=\lim \left\{X_{i}, f_{i}^{i+1}\right\}$ is a self-entwined, circle-like continuum (hence we may assume for each $i$ that $\operatorname{deg}\left(f_{i}^{i+1}\right)>0$ and 
$\left.R\left(f_{i}^{i+1}\right)>1\right)$, then we say that $X$ is strongly self-entwined if

$$
R\left(f_{i}^{i+1}\right)>\operatorname{deg}\left(f_{i}^{i+1}\right) \text { for each } i .
$$

A solenoid is a circle-like continuum which is the inverse limit of an inverse sequence such that each bonding map is one of the complex functions $\left\{w=z^{n}\right\}_{n=1}^{\infty}$. A pseudo-circle is a non-arc-like, hereditarily indecomposable, circle-like plane continuum [4].

1. Mapping solenoids onto circle-like continua. We proceed immediately to the main theorem.

Theorem 1. No solenoid can be mapped onto a strongly selfentwined, circle-like continuum.

Proof. Let $X=\lim \left\{X_{i}, f_{i}^{i+1}\right\}$ be a strongly self-entwined, circlelike continuum. We may assume that $\operatorname{deg}\left(f_{i}^{i+1}\right) \geqq 1$ and

$$
R\left(f_{i}^{i+1}\right)>\operatorname{deg}\left(f_{i}^{i+1}\right), i=1,2, \cdots .
$$

Let $S=\lim \left\{S_{i}, g_{i}^{i+1}\right\}$ be the 2-solenoid; we may assume that each bonding map $g_{i}^{i+1}$ is the complex function $w=z^{2}$. We prove the theorem for $S$; the proof of the general case is similar.

Suppose that there exists a map $f$ of $S$ onto $X$. Let $\left\{\varepsilon_{n}\right\}$ be a decreasing sequence of positive numbers converging to zero and bounded above by $1 / 2$. The existence of $f$ implies the existence of an infinite diagram

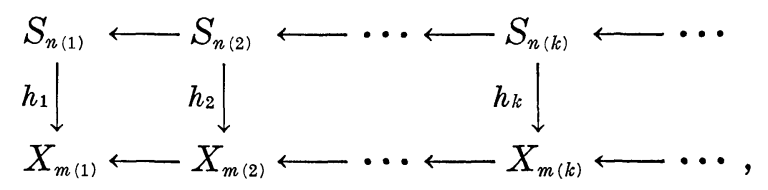

where $\{m(k)\}$ and $\{n(k)\}$ are increasing sequences of positive integers and where every subdiagram

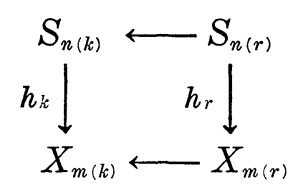

is $\varepsilon_{k}$-commutative for all $r \geqq k$. See [2, Theorem 1] for details.

Since each $\varepsilon_{k}<1 / 2$, Diagram (2) and Lemma 4 of [4] assure us that

$$
\left.\operatorname{deg}\left(h_{k} \circ g_{n(k)}^{n(r)}\right)=\operatorname{deg}\left(f_{m(k)}^{m(r)}\right) \circ h_{r}\right)(r>k) .
$$

We show (as in Theorem 5 of [3]) that the revolving number of 
$h_{k} \circ g_{n(k)}^{n(r)}$ is less than that of $f_{m(k)}^{m(r)} \circ h_{r}$. Now it is not necessary that the two revolving numbers be equal, since the two composite maps may differ by $\varepsilon_{k}$; since $\varepsilon_{k}<1 / 2$, however, the revolving numbers can differ by no more than two (one at each end of a defining interval). For this reason, we add two to $R\left(h_{k} \circ g_{n(k)}^{n(r)}\right)$ in the last inequality.

Because the bonding maps of the solenoid are so smooth, the inequality of Theorem 1 of [3] is actually an equality. Therefore,

$$
\begin{aligned}
R\left(h_{1} \circ g_{n(1)}^{n(r)}\right) & =R\left(g_{n(1)}^{n(r)}\right) \cdot \operatorname{deg}\left(h_{1}\right)-\operatorname{deg}\left(h_{1}\right)+R\left(h_{1}\right) \\
& =\operatorname{deg}\left(g_{n(1)}^{n(r)}\right) \cdot \operatorname{deg}\left(h_{1}\right)-\operatorname{deg}\left(h_{1}\right)+R\left(h_{1}\right) \\
& =\operatorname{deg}\left(h_{1} \circ g_{n(1)}^{n(r)}\right)-\operatorname{deg}\left(h_{1}\right)+R\left(h_{1}\right) .
\end{aligned}
$$

On the other hand, repeated applications of Theorem 1 of [3] imply that

$$
R\left(f_{m(1)}^{m(r)}\right) \geqq \sum_{i=3}^{r}\left[R\left(f_{m(i-1)}^{m(i)}\right) \cdot \operatorname{deg}\left(f_{m(1)}^{m(i-1)}\right)-\operatorname{deg}\left(f_{m(1)}^{m(i-1)}\right]+R\left(f_{m(1)}^{m(2)}\right) .\right.
$$

Since

$$
R\left(f_{m(i-1)}^{m(i)}\right) \geqq 1+\operatorname{deg}\left(f_{m(i-1)}^{m(i)}\right) \text { and } \operatorname{deg}\left(f_{m(i-1)}^{m(i)}\right) \geqq 1,
$$

we have

$$
\begin{aligned}
R\left(f_{m(1)}^{m(r)}\right) & \geqq \sum_{i=2}^{r} \operatorname{deg}\left(f_{m(1)}^{m(i)}\right) \\
& \geqq \operatorname{deg}\left(f_{m(1)}^{m(r)}\right)+\sum_{i=2}^{r-1}\left(\operatorname{deg} f_{m(1)}^{m(i)}\right) \\
& \geqq \operatorname{deg}\left(f_{m(1)}^{m(r)}+(r-2) .\right.
\end{aligned}
$$

Again applying Theorem 1 of [3], we find that

$$
\begin{aligned}
R\left(f_{m(1)}^{m(r)} \circ h_{r}\right) \geqq & R\left(h_{r}\right) \cdot \operatorname{deg}\left(f_{m(1)}^{m(r)}\right)-\operatorname{deg}\left(f_{m(1)}^{m(r)}\right)+R\left(f_{m(1)}^{m(r)}\right) \\
\geqq & \operatorname{deg}\left(h_{r}\right) \cdot \operatorname{deg}\left(f_{m(1)}^{m(r)}\right)-\operatorname{deg}\left(f_{m(1)}^{m(r)}\right) \\
& \quad+\operatorname{deg}\left(f_{m(1)}^{m(r)}\right)+(r-2) \\
\geqq & \operatorname{deg}\left(f_{m(1)}^{m(r)} \circ h_{r}\right)+r-2 \\
\geqq & \operatorname{deg}\left(h_{1} \circ g_{n(1)}^{n(r)}\right)+r-2 \\
\geqq & R\left(h_{1} \circ g_{n(1)}^{n(r)}\right)+\operatorname{deg}\left(h_{1}\right)-R\left(h_{1}\right)+r-2 .
\end{aligned}
$$

If we choose $r$ to exceed $R\left(h_{1}\right)-\operatorname{deg}\left(h_{1}\right)+5$, then we obtain

$$
R\left(f_{m(1)}^{m(r)} \circ h_{r}\right)>R\left(h_{1} \circ g_{n(1)}^{n(r)}\right)+2 .
$$

This contradiction establishes the theorem.

Corollary 1. No solenoid can be mapped onto a self-entwined, circle-like, plane continuum. 
Proof. It suffices to show that each self-entwined, circle-like, plane continuum $C$ is strongly self-entwined. Since $C$ is self-entwined, $C$ is the inverse limit of an inverse sequence $\left\{C_{i}, f_{i}^{i+1}\right\}$, where $R\left(f_{i}^{i+1}\right)>1$ and $\operatorname{deg}\left(f_{i}^{i+1}\right)>0$, for each $i$. By Theorem 3 of [1], we may assume, by choosing a subsequence if necessary, that $\operatorname{deg}\left(f_{i}^{i+1}\right)=1$, for all $i$. Therefore, $R\left(f_{i}^{i+1}\right)>\operatorname{deg}\left(f_{i}^{i+1}\right)$, and $C$ is strongly selfentwined.

Corollary 2. No solenoid can be mapped onto a $V_{n}$.

Corollary 3. No solenoid can be mapped onto the pseudo-circle. [4].

\section{BIBLIOGRAFHY}

1. R. H. Bing, Embedding circle-like continua in the plane, Canad. J. Math., 14 (1962), 113-128.

2. J. Mioduszewski, Mappings of inverse limits, Colloq. Math., 10 (1963), 39-44.

3. J. T. Rogers, Jr., Mapping the pseudo-arc onto circle-like, self-entwined continua, Mich. J. of Math., 17 (1970), 91-96.

4. - The pseudo-circle is not homogeneous, Trans. Amer. Math. Soc., 148 (1970), 417-428.

5. - Pseudo-circles and universal circularly chainable continua, Illinois J. Math., 14 (1970), 222-237.

6. J. W. Rogers, Jr., On mapping indecomposable continua onto certain chainable indecomposable continua, Proc. Amer. Math. Soc., 25 (1970), 449-456.

Received October 10, 1969 and in revised form September 21, 1970.

TUlane UNIVERSity 


\section{PACIFIC JOURNAL OF MATHEMATICS}

\section{EDITORS}

H. SAMELSON

Stanford University

Stanford, California 94305

C. R. Новву

University of Washington

Seattle, Washington 98105
J. DUGundJI

Department of Mathematics

University of Southern California

Los Angeles, California 90007

RICHARD ARENS

University of California

Los Angeles, California 90024

\section{ASSOCIATE EDITORS}
E. F. BECKENBACH
B. H. NeumanN
F. WOLF
K. YOSHIDA

\section{SUPPORTING INSTITUTIONS}
UNIVERSITY OF BRITISH COLUMBIA
CALIFORNIA INSTITUTE OF TECHNOLOGY
UNIVERSITY OF CALIFORNIA
MONTANA STATE UNIVERSITY
UNIVERSITY OF NEVADA
NEW MEXICO STATE UNIVERSITY
OREGON STATE UNIVERSITY
UNIVERSITY OF OREGON
OSAKA UNIVERSITY
UNIVERSITY OF SOUTHERN CALIFORNIA
STANFORD UNIVERSITY
UNIVERSITY OF TOKYO
UNIVERSITY OF UTAH
WASHINGTON STATE UNIVERSITY
UNIVERSITY OF WASHINGTON
AMERICAN MATHEMATICAL SOCIETY CHEVRON RESEARCH CORPORATION TRW SYSTEMS
NAVAL WEAPONS CENTER 


\section{Pacific Journal of Mathematics}

\section{Vol. 37, No. $1 \quad$ January, 1971}

Gregory Frank Bachelis and Haskell Paul Rosenthal, On unconditionally

converging series and biorthogonal systems in a Banach space .........

Richard William Beals, On spectral theory and scattering for elliptic

operators with singular potentials .........................

J. Lennart (John) Berggren, Solvable and supersolvable groups in which every element is conjugate to its inverse ........................ 21

Lindsay Nathan Childs, On covering spaces and Galois extensions ..........

William Jay Davis, David William Dean and Ivan Singer, Multipliers and

unconditional convergence of biorthogonal expansions..............

Leroy John Derr, Triangular matrices with the isoclinal property ............

Paul Erdős, Robert James McEliece and Herbert Taylor, Ramsey bounds for

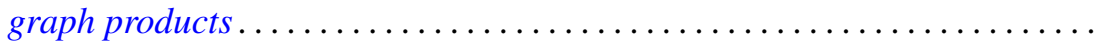

Edward Graham Evans, Jr., On epimorphisms to finitely generated

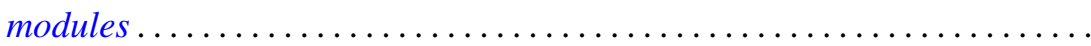

Hector O. Fattorini, The abstract Goursat problem ................. 51

Robert Dutton Fray and David Paul Roselle, Weighted lattice paths .........

Thomas L. Goulding and Augusto H. Ortiz, Structure of semiprime $(p, q)$

radicals ...........................................

E. W. Johnson and J. P. Lediaev, Structure of Noether lattices with join-principal maximal elements ....

David Samuel Kinderlehrer, The regularity of minimal surfaces defined over

slit domains

Alistair H. Lachlan, The transcendental rank of a theory. .

Frank David Lesley, Differentiability of minimal surfaces at the boundary ...

Wolfgang Liebert, Characterization of the endomorphism rings of divisible torsion modules and reduced complete torsion-free modules over complete discrete valuation rings....

Lawrence Carlton Moore, Strictly increasing Riesz norms.

Raymond Moos Redheffer, An inequality for the Hilbert transform ...

James Ted Rogers Jr., Mapping solenoids onto strongly self-entwined,

circle-like continua..........................

Sherman K. Stein, B-sets and planar maps ................... 217

Darrell R. Turnidge, Torsion theories and rings of quotients of Morita

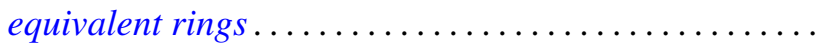

Fred Ustina, The Hausdorff means of double Fourier series and the principle of localization ................................

Stanley Joseph Wertheimer, Quasi-compactness and decompositions for arbitrary relations.

Howard Henry Wicke and John Mays Worrell Jr., On the open continuous images of paracompact $\check{C}$ ech complete spaces... 